\title{
O Malandro carioca e o "Maloqueiro" paulista em diálogo através da canção
}

\author{
Márcia Cristina Roque Corrêa Marques*
}

\begin{abstract}
Resumo: o presente trabalho analisa as canções "Lenço no Pescoço" e "Rapaz Folgado", dos cariocas Wilson Batista e Noel Rosa, e "Saudosa Maloca", do paulista Adoniran Barbosa, a fim de resgatar as figuras do malandro, do sambista e do "maloqueiro" por elas apresentadas. Como ponto de partida, tomamos o fato de que, tanto as canções cariocas quanto a canção paulista, resgataram o momento de expansão e industrialização das duas cidades, com aumento da massa urbana e acentuada diferenciação social, com consequiente exclusão da massa operária. Apesar de compostas em épocas diferentes, as canções têm o mesmo movimento, ao criar imagens bastante fortes dos personagens do drama urbano. Contudo, cada uma delas cria uma imagem particular, de um lado o malandro carioca que não se submete nunca à sociedade que o oprime e de outro o conformado "maloqueiro" paulista.
\end{abstract}

\begin{abstract}
This work aims at analyzing the songs "Lenço no Pescoço" by Wilson Batista, "Rapaz Folgado" by Noel Rosa and "Saudosa Maloca" by Adoniran Barbosa in order to have an overview of the characters created by these songs and the way in which they reacted to the processes of industrialization and consequent social exclusion which resulted from the increase of the urban masses in Rio de Janeiro and in São Paulo at the time in which they were composed.
\end{abstract}

A canção é, sem dúvida, uma manifestação cultural bastante particular no Brasil, tendo em seu berço uma marca bastante popular e passando por momentos de elitização ao longo de sua história. José Ramos Tinhorão em seu História Social da Música Popular Brasileira (1998) traça um paralelo entre os rumos da música popular no Brasil e os principais eventos sociais, políticos e econômicos que, segundo o autor, influenciaram o desenvolvimento desta manifestação cultural.

No presente trabalho, visamos analisar e contrastar figuras estereotipadas criadas por canções do Rio de Janeiro e de São Paulo, usando as composições de autores cariocas "Lenço

\footnotetext{
* Licenciada em Letras e atualmente é acadêmica do curso de Mestrado em Literaturas Brasileira e LusoAfricanas pela Universidade Federal do Rio Grande do Sul, com especialização em Literatura Brasileira pela mesma Universidade.
} 
no Pescoço" de Wilson Batista e "Rapaz Folgado" de Noel Rosa e "Saudosa Maloca" do paulista Adoniran Barbosa.

Como ponto de partida da análise, tomamos por base o fato de que as duas canções foram compostas em momentos em que as cidades do Rio de Janeiro, nos anos 20, e de São Paulo, nos anos 50, vivenciavam momentos que tinham alguns traços semelhantes e ambas também enfrentaram momentos de profunda expansão e modernização, com aumento da população urbana devido à migração interna no país. As duas cidades iniciaram nestas épocas distintas, e devido a estes movimentos, os processos de separação drástica entre as classes sociais, sendo que, em cada uma delas, a expressão musical acabou por ser uma marca destas classes menos favorecidas.

Tratando do Rio de Janeiro, Tinhorão (1998) considera o surgimento do samba como um derivado do sucesso das revistas do início do século XX. Este tipo de divertimento, associado aos blocos de rua carnavalescos, era o que mais atingia as camadas populares no Brasil e ajudou a conferir um caráter eminentemente brasileiro "ao gênero, na base do aproveitamento de tipos populares como o matuto, o coronel fazendeiro, o português, a mulata, o guarda, o capadócio (o fadista português depois chamado de malandro no Brasil), o funcionário público, o camelô, etc.” (TINHORÃO, 1998, p. 238).

Neste ponto, localizamos o início da utilização de figuras populares como temática das canções populares. Com o advento da tecnologia de gravação mecânica de sons, a revista e o carnaval passaram a ser uma das formas mais intensas de contato das camadas mais baixas da população com a música, uma vez que a gravação e o equipamento para a reprodução de sons tinham um preço inacessível a esta parcela da população.

Tinhorão (1998) chama a atenção para o fato de o Rio de Janeiro ter sido um reduto da migração interna de trabalhadores no país nesta época, explicando assim o crescimento da massa popular urbana trabalhadora nesta cidade. Com a falta de acesso aos meios culturais das classes mais abastadas, esta camada da população encontrou no samba a forma de expressão livre que abrigava esta nova experiência urbana.

Era natural, portanto, que a figura do malandro carioca caracterizada em uma canção pudesse causar tanto desconforto a Noel Rosa, um dos compositores tratados no presente trabalho e profundamente empenhado em seu ofício de sambista, pois, se por um lado se constituía num retrato do que se passava em determinadas camadas sociais do país, por outro vinha a denegrir a imagem do sambista carioca. Foi neste momento que surgiu o famoso impasse entre os compositores Noel Rosa e Wilson Batista. 
A canção "Rapaz Folgado", de Noel Rosa, foi composta em 1933 como uma resposta a Wilson Batista, que havia composto "Lenço no Pescoço", canção na qual criava um estereótipo bastante negativo, na visão de Noel Rosa, a respeito da figura do malandro carioca, associado ao sambista.

Em "Lenço no Pescoço", Batista caracterizava o malandro da seguinte forma:

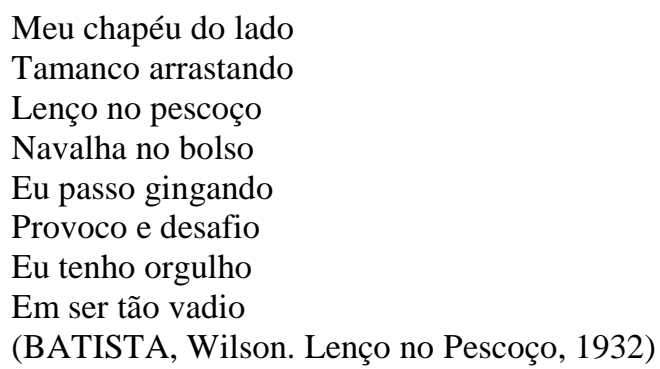

O malandro carioca estava aí caracterizado, não somente em sua indumentária, mas também em seu orgulho em vadiar. A imagem evoca a ginga daquele que tira proveito das situações, é "safo" e não tem medo de nada.

No Pequeno Dicionário Brasileiro da Língua Portuguesa (LIMA \& BARROSO, 1949, p.776), o termo é definido como "sujeito que costuma abusar da confiança dos outros; ou que não trabalha e vive de expedientes; vadio; gatuno." Ou seja, um indivíduo que despreza o trabalho e vive de "expedientes", enganando e roubando. Já neste verbete, verificase uma caracterização altamente pejorativa. Em nosso tempo, buscando nos meios eletrônicos a definição para este tipo, encontramos no site http://pt.wikipedia.org a entrada para o verbete "malandragem" colocada da seguinte maneira:

Malandragem define-se como um conjunto de artimanhas utilizadas para se obter vantagem em
determinada situação (vantagens estas muitas vezes ilícitas). Caracteriza-se pela engenhosidade
e sutileza. Sua execução exige destreza, carisma, lábia e quaisquer características que permitam
a manipulação de pessoas ou resultados, de forma a obter o melhor destes, e da maneira mais
fácil possível. Contradiz a argumentação lógica, o labor e a honestidade, pois a malandragem
pressupõe que tais métodos são incapazes de gerar bons resultados. [...] neste a integridade de
instituições e de indivíduos é efetivamente lesada, e de forma juridicamente definível como
dolosa. No entanto, a malandragem bem-sucedida pressupõe que se obtenham vantagens sem
que sua ação se faça perceber. Em termos mais populares, o "malandro" "engana" o "otário"
(vítima) sem que este perceba ter sido enganado. A malandragem é descrita no imaginário
popular brasileiro como uma ferramenta de justiça individual. Perante a força das instituições
necessariamente opressoras, o indivíduo "malandro" sobrevive manipulando pessoas,
enganando autoridades e driblando leis, de forma a garantir seu prejudicado bem-estar.
(http://pt.wikipedia.org/wiki/Malandragem) Comparando-se as duas definições com a letra composta por Wilson Batista, verificamos que a figura criada pelo compositor é quase que um resumo da concepção atual do malandro. No mesmo site, há uma referência ao samba de Batista como o "hino da malandragem", que liga a canção ao surgimento da figura do malandro, afirmando ainda que foi nos sambas cariocas que este "personagem" foi mais exaltado. 
Na seqüência da canção o compositor ainda coloca:

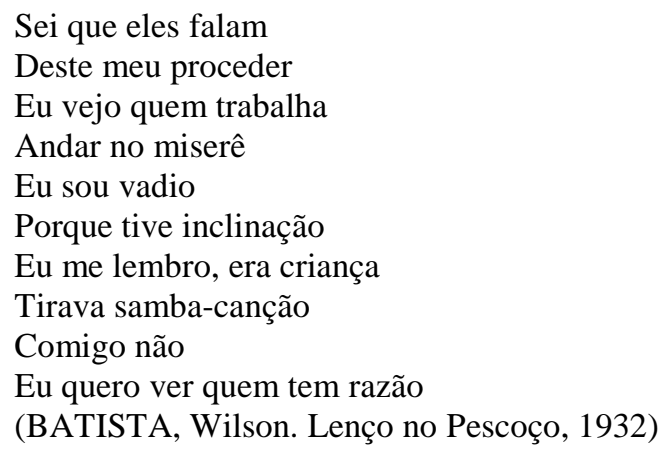

Verificamos que o autor denigre a condição do trabalhador, afirmando que o trabalho nada traz em benefício deste, que aponta uma associação entre a figura do sambista e a do vagabundo.

A esta canção, Noel Rosa respondeu com "Rapaz Folgado", na qual ridicularizava a imagem criada por Wilson Batista.

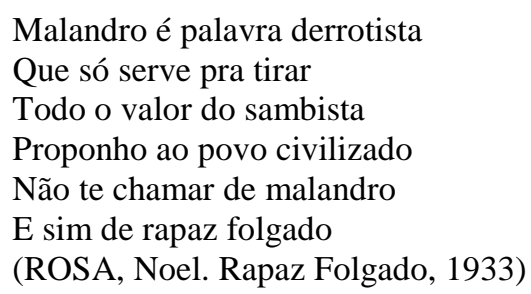

Em sua composição, Noel Rosa demonstrava uma grande preocupação com a imagem do sambista sendo associada à do malandro e propôs uma mudança de termos.

Segundo Luiz Tatit (2002), para Noel Rosa a canção era o samba e o autor enfatiza a forma como o compositor via o sambista, sempre tentando elevar sua figura:

\footnotetext{
Noel impressionava pela altivez com que tratava o samba. Nunca pôs em dúvida o valor do sambista. Seu orgulho vaza pelos textos e convence o ouvinte pela compatibilidade que mantém com as respectivas melodias. Nunca se pautou por fontes eruditas ou por idioletos populares estereotipados. Exibia consciência surpreendente da linguagem do samba. (TATIT, 2002, p.29-30)
}

Noel Rosa tinha, como já dito, uma grande preocupação com a imagem do sambista e com uma caracterização positiva do samba. Em suas composições, tentava alcançar um perfeito equilíbrio entre melodia e letra (que tratavam comumente de situações cotidianas ou amorosas) e, deste equilíbrio, chamado por Tatit (2002) de "malabarístico", resultava o samba. Seu texto era o "texto ideal para a canção, exatamente porque (Noel) se preocupava com o samba e não com a poesia" (TATIT, 2002, p.30).

Tatit (2002, p.31) também salienta que o conteúdo das canções de Noel era de "cunho eminentemente pessoal" e que seu objetivo maior era traçar "um conjunto de regras básicas para a composição brasileira". 
Se a polêmica em torno da figura do malandro era uma jogada de marketing entre os dois compositores ou não, o fato é que, através de suas canções, mais que uma polêmica musical, temos de um lado uma caracterização que ficou, de certa forma, eternizada no imaginário popular e de outro uma tentativa de desligar esta imagem negativa do sambista carioca. Negativa porque caracterizava o sambista como alguém que tirava vantagem de tudo, de forma inescrupulosa, mas também colocava o indivíduo das classes mais baixas cariocas como aquele que escapa das adversidades até com certa altivez, sem dobrar-se perante as regras da sociedade e sem importar-se com elas, fazendo uso até mesmo de esquemas ilícitos para contornar estas adversidades.

Esta figura caracterizava o malandro carioca como aquele que luta, mesmo que de forma negativa, contra a situação na qual se encontra, sem se render e sem se conformar.

Em oposição a este ideário, temos a figura da pessoa humilde da cidade de São Paulo retratada na canção "Saudosa Maloca" de Adoniran Barbosa, considerado por Antonio Candido (apud MATOS, 2001) como a voz da cidade de São Paulo.

O momento da criação desta canção é posterior ao da canção de Noel Rosa.A II Guerra Mundial terminara e o Brasil vivia a consumação do que já se prenunciava à época de Noel e Batista. O país tinha enfim caído nas malhas da dominação econômica imposta pelos Estados Unidos (TINHORÃO, 1998), e a rápida expansão se dava às custas do sucateamento da matéria nacional. São Paulo entrou numa época de crescimento, modernização e industrialização. O processo de migração nordestina, vivenciado no Rio de Janeiro anos antes, era intensificado em São Paulo, aumentando a massa urbana que se dividia cada vez mais segundo as classes sociais e o tipo de atividade desenvolvida pelos moradores. É tratando dessa época que Maria Izilda Santos de Matos (2001) aponta para a invenção da chamada "paulistaneidade", ou seja, o sentimento de ufanismo regional por viver-se na "cidade que mais cresce no país" e toda uma gama de novos desejos e padrões que, em choque com valores mais tradicionais, gerava um ambiente urbano cheio de nostalgia, devido às intensas e constantes transformações que a cidade vivia (MATOS, 2001).

A canção "Saudosa Maloca" retrata exatamente este momento de tensão, em que o novo abre caminho à força, deixando nos indivíduos um ar de saudade e nostalgia. Márcio Coelho (2003), em uma abordagem semiótica desta canção, ressalta seu caráter saudosista e melancólico, em que uma melodia aparentemente feliz e carregada de emoções positivas traz em sua letra uma dor profunda de perda e um apego muito grande ao que foi destruído, o que é chamado pelo autor de "felicidade de ser triste". 
Se pensarmos nas propostas de Coelho (2003) e de Matos (2001) em conjunto, veremos que ambas as abordagens traduzem o mesmo sentimento díspar: a euforia da modernidade em confronto com a melancolia da perda de raízes, como mostra o seguinte trecho:

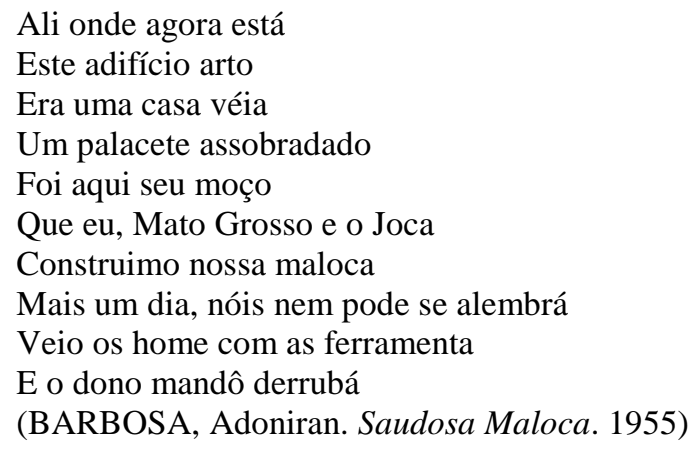

Ao contar a história, o homem humilde demonstra sua comoção ao afirmar que "nóis nem pode se alembrá" e assume a condição de mero espectador da destruição daquilo que conhecia como lar para que o progresso pudesse se estabelecer, como dito no trecho a seguir:

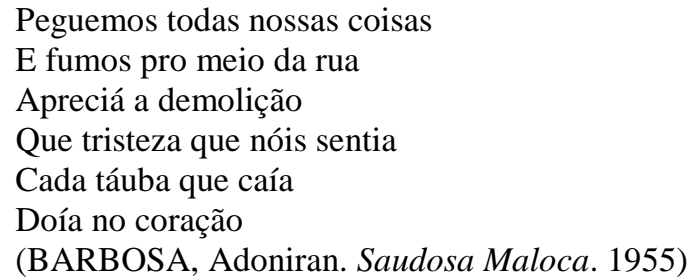

Apesar da dor sentida, os homens buscam conformar-se e acabam por buscar consolo na religiosidade, sem ação, apenas com resignação.

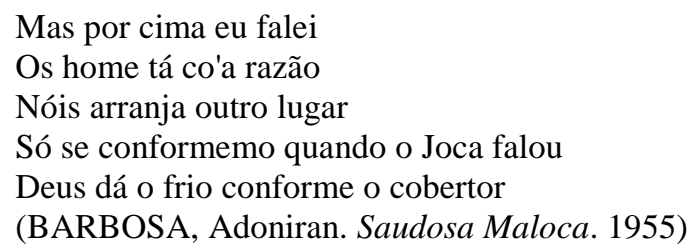

O fazer musical surge também na canção de Adoniran, não de forma a definir esta atividade, mas como forma de alívio ao sofrimento dos homens.

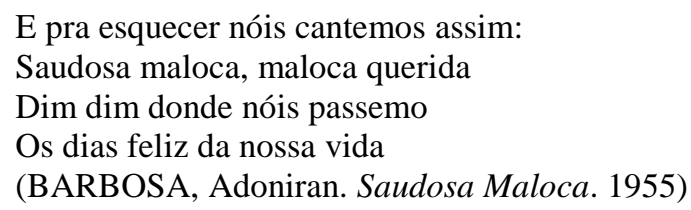

Comparando-se as canções de Wilson Batista, Noel Rosa e Adoniran Barbosa, pode-se ter uma tomada de dois momentos vividos pelas duas maiores cidades brasileiras à época. No Rio de Noel e Batista, capital do país e em franca expansão no início do século, podemos encontrar os ecos da população de camada mais baixa que, excluída do processo de expansão, 
criava uma nova forma de subsistir e revidar o processo de exclusão: a malandragem. A preocupação evidenciada por Noel com a imagem do sambista demonstra que, para o carioca, o lugar do sambista tinha uma conotação de grande importância e que a associação com este novo espírito social não era agradável. Contudo, seja o malandro de Batista seja o sambista de Noel, ambos tinham uma ação combativa perante a sociedade e demonstravam querer seu lugar demarcado, um através de atitudes consideradas ilícitas, outro por uma valorização da condição do sambista. Batista acabou por abrir caminho para uma figura que se tornou definição do "jeitinho brasileiro" (DAMATTA, 1984), e Noel tentou caracterizar a função de sambista, fato que rende seus frutos até hoje, como se pode verificar na forma como o samba e os sambistas são exaltados no país em épocas de Carnaval (embora logo depois voltem a se tornar figuras anônimas).

O homem humilde de Adoniran, ao contrário, ao ser excluído da cidade em evolução, conformou-se, buscou consolo e foi “pegá as paia nas grama do jardim”. Não se vê neste homem, que viveu a mesma situação do carioca, a atitude combativa do outro. A linguagem usada pelo compositor marca bem a identidade deste homem, colocando em oposição o rural e o urbano e demarcando o lugar daqueles que vinham à cidade grande buscar melhores condições. Esta mesma cidade, que antes havia sido seu sonho e a promessa de uma vida melhor, torna-se seu algoz e o coloca à margem, lugar onde ele permaneceu placidamente, sofrendo em silêncio e cantando para espantar a tristeza.

É bem verdade que hoje podemos ler esta canção como uma denúncia da situação da época (MATOS, 2001), mas este é o olhar de quem recebe a canção com olhos críticos e atuais. A imagem posta pela canção é a do homem humilde que se submeteu e foi devorado pela cidade e pelo progresso.

Canções diferentes e de épocas diferentes, encontram um ponto de convergência ao retratarem o mesmo processo vivido pelas duas cidades, ressaltando as peculiaridades da forma como os acontecimentos foram registrados pelos artistas. Como forma peculiar de expressão popular estas obras permanecem até hoje no repertório das canções populares brasileiras como marcas de identidade de um Brasil que, longe de abrigar as formas de expressão popular, as coloca à margem. Contudo, é neste processo que elas ganham voz, retratando, denunciando e fixando paradigmas, como é o caso da figura do malandro carioca e do "maloqueiro" paulista.

A partir dessa análise vemos a importância dos estudos cada vez mais difundidos da canção popular brasileira como parte do movimento literário nacional. Sua caracterização como produto da intelectualidade e da cultura de nosso povo nos faz repensar sua inserção no 
campo dos estudos literários. Cavalcante (2004) em seus estudos sobre a canção popular urbana de Porto Alegre afirma que

a canção, através de seus compositores e intérpretes, representa importante papel na sociedade, pois, assim como a literatura, é uma forma de manifestação histórica e cultural de um determinado período ou grupo social.

A canção popular brasileira é reconhecida por críticos e especialistas como uma das mais diversificadas do mundo. Não só surgem novos ritmos e interpretações em um determinado período, como convivem diversos movimentos poético-musicais ao mesmo tempo. (CAVALCANTE, 2004, p.7)

Em seus estudos, aproxima a canção à poesia e afirma que

dar voz às manifestações literárias tem se tornado ponto fundamental para o desenvolvimento da literatura. A canção se insere nesse universo exigindo legitimidade, argumentando em seu favor a qualidade da elaboração das letras e o aumento de um público que vem intercalando cada vez mais o hábito de ouvir ao da leitura. Como bem percebeu Jorge Furtado "as letras de música suprem parte da necessidade que todos nós temos de ouvir e dizer poesia." (CAVALCANTE, 2004, p.8)

Assim, tomada como parte de um conjunto de produções artísticas de uma sociedade, motivada por esta e para esta, da qual é produto e alimento, a canção tem a capacidade, assim como a literatura, de trabalhar com assuntos que necessitam ser trazidos à cena do debate. Também operando com a matéria escrita, mas tendo a musicalidade aliada à sua produção, a canção é ao mesmo tempo semelhante e diferente da literatura como tradicionalmente a reconhecemos. No caso das canções em estudo, toda uma formação de tipos e costumes foi retratada em verso e sons, denunciando num primeiro instante uma formação social para depois conformar o tipo social retratado como um dos tipos freqüentes e de importância fundamental para a compreensão do funcionamento de nossa sociedade atual.

\section{Referências}

CAVAlCANTE, Rita de Cássia. Porto Alegre em canto e verso:vinte e poucos anos de canção popular urbana. Dissertação de Mestrado. Porto Alegre: UFGRS, 2004.

COELHO, Márcio. A Paixão e a Passionalização em Saudosa Maloca. Cadernos de Semiótica Aplicada. Vol.1, no 2, dezembro 2003.

DAMATTA, Roberto. O que faz o brasil, Brasil?. Rio de Janeiro: Rocco, 1984.

DANTAS, André. Malandro que é malandro... Morpheus - Revista Eletrônica em Ciências Humanas. Ano 02, número 03,2003.

LIMA, Hildrebando de \& BARROSO, Gustavo. Pequeno Dicionário Brasileiro da Língua Portuguesa. Rio de Janeiro: Editora Civilização Brasileira, 1949.

MATOS, Maria Izilda Santos de. A Cidade que mais Cresce no Mundo: São Paulo território de Adoniran Barbosa. São Paulo Perspec. Vol. 15 no3 São Paulo July/Sept. 2001. 
TATIT, Luiz. O Cancionista. São Paulo: Edusp, 2002.

Elementos para a Análise da Canção Popular. Cadernos de Semiótica Aplicada. Vol.1, no 2, dezembro 2003.

TINHORÃO, José Ramos. História Social da Música Popular Brasileira. São Paulo: Editora 34, 1998.

SEVERIANO, Jairo \& MELlO, Zuza Homem. A Canção no Tempo: 85 Anos de Músicas Brasileira. Vol 1: 1901-1957. São Paulo: Editora 34, 1998.

\section{Referências eletrônicas}

Malandragem. http://pt.wikipedia.org/wiki/Malandragem. Acesso em 12/03/2007.

ROSA, Noel. Rapaz Folgado (letra). Acesso em 02/03/2007

http://www.mpbnet.com.br/musicos/ione.papas/letras/rapaz_folgado.htm

BATISTA. Wilson. Lenço no Pescoço (letra). Acesso em 02/03/2007

http://www.lyricsspot.com/wilson+batista-len+o+no+pesco+o-lyrics-658647.html

BARBOSA, Adoniran. Saudosa maloca (letra). Acesso em 02/03/2007.

http://www2.uol.com.br/cante/lyrics/Adoniram_Barbosa_-_Saudosa_maloca.htm 